Myocardial function was determined by echocardiogram (2-D, M-mode, tissue and conventional Doppler techniques).

Results Traditional cardiovascular risk factors were similar in PAPS and controls. PAPS patients had $55.6 \%$ of venous events, $55.6 \%$ arterial and $22.2 \%$ obstetric features, stroke was observed in $33.3 \%$, deep venous thrombosis in $44.4 \%$, livedo reticularis in $66.7 \%$. $88.9 \%$ were positive for IgG and/ or IgM anticardiolipina antibodies and $66.7 \%$ were positive for lupus anticoagulant. Conventional echocardiographic data was not altered in all parameters evaluated, comparing patients and controls. Regarding tissue Doppler echocardiogram data, a lower S' of lateral wall of left ventricle was observed in PAPS in comparison to controls [0.085 (0.007$0.12)$ vs. $0.12(0.09-0.13), p=0.004]$ as well as $A^{\prime}$ wave of the septum [0.07 $(0.06-0.08)$ vs. $0.09(0.07-0.11), p=0.02]$.

Conclusions Our data support the notion that PAPS patients have asymptomatic myocardial dysfunction evidenced by tissue Doppler echocardiography.

\section{ANTIPHOSPHOLIPID ANTIBODY SYNDROME PRESENTING AS SPONTANEOUS HEPATIC RUPTURE}

I Cunanan*, A Corpuz, VP Sta Maria, PA Casem. Ilocos Training and Regional Medical Centre, Internal Medicine, City of San Fernando, Philippines

10.1136/lupus-2017-000215.61

Background and aims Spontaneous hepatic rupture (SHR) is a rare peripartum complication and usually occurs among patients with pre-eclampsia, eclampsia or HELLP syndrome. We report a case of a 29 year old primigravid woman with fetal death in utero and spontaneous hepatic rupture secondary to undiagnosed Antiphospholipid Antibody Syndrome (APAS). Despite its uncommonness, a high index of suspicion

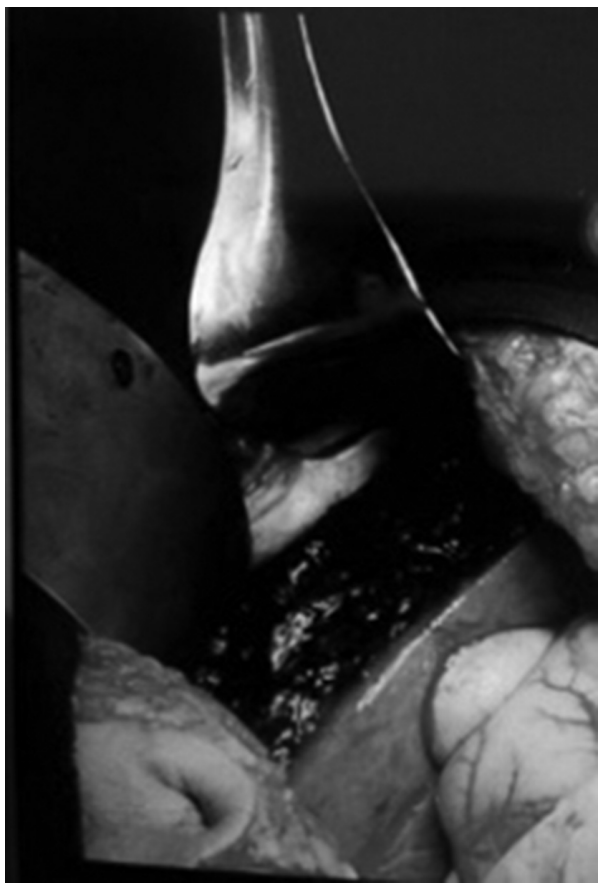

Abstract 61 Figure 1

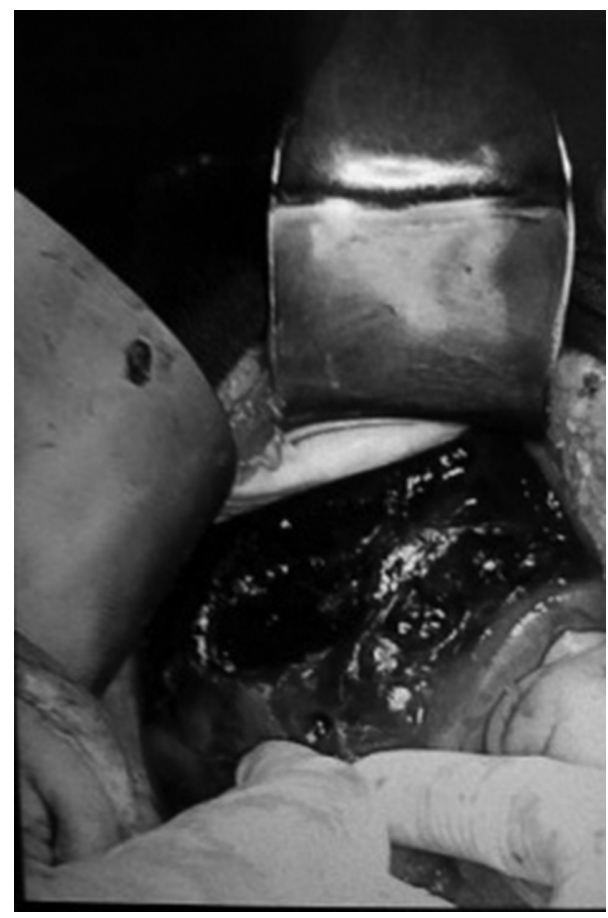

Abstract 61 Figure 2

Abstract 61 Table 1 Revised SAPPORO Classification criteris for the antiphospholipid antibody syndrome.

\begin{tabular}{|c|c|}
\hline & Clinical criteria \\
\hline \multirow[t]{2}{*}{$\checkmark$} & $\begin{array}{l}\text { 7. Vascular thrombosis } \\
\text { One or more clinical episodes of arterial, venous, or small vessel } \\
\text { thrombosis }\end{array}$ \\
\hline & 2. Pregnancy morbority \\
\hline 2 & $\begin{array}{l}\text { a. One of more unexplarine retal deaths of a morphologically } \\
\text { normal fetus at or beyond the } 10^{\circ} \text { week of gestation }\end{array}$ \\
\hline $\bar{x}$ & $\begin{array}{l}\text { b. One of more pre-term births of a morphologically normal } \\
\text { neonate }\end{array}$ \\
\hline$x$ & $\begin{array}{l}\text { C. Detore the 34" week of gestation becasuse or: W eclampsia or } \\
\text { severe pre-eclampsia or (i) recognized features of placental } \\
\text { insufficiency }\end{array}$ \\
\hline \multirow[t]{2}{*}{$x$} & $\begin{array}{l}\text { d. Three of more Unexplained consecutive spontaneous } \\
\text { miscarniages before the } 10^{n} \text { week of gestation, with maternal } \\
\text { anatomic or hormonal abnormalifes and paternal and maternal } \\
\text { chromosomal causes excluded }\end{array}$ \\
\hline & Laboratory criteria \\
\hline$\nabla$ & $\begin{array}{l}\text { 1. Lupus anticosgutant (La) present in plasma, on two or more } \\
\text { occasions at least } 12 \text { weeks apart }\end{array}$ \\
\hline$x$ & 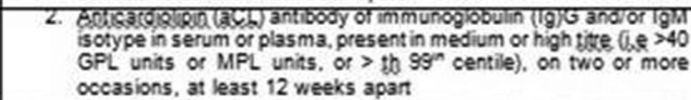 \\
\hline $\bar{x}$ & 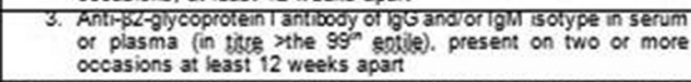 \\
\hline$x$ & 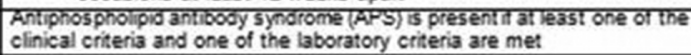 \\
\hline
\end{tabular}

for an autoimmune disease such as APAS to prevent maternal and fetal complications is recommended.

Presenting a 29 year old, primigravid of 32 weeks age of gestation was admitted due to epigastric pain, hypotension and decreased fetal movement. She delivered to a dead male neonate via Emergency Low Segment Transverse Caesarean Section. Hemoperitonium and active bleeding from the liver were noted intraoperatively.

Methods Patient was managed as spontaneous hepatic rupture. APAS was considered and diagnosed via the Revised SAPPORO Criteria. HELLP syndrome and pre-eclampsia were ruled out by clinical and laboratory parameters. 
Results Hepatic packing with drainage and blood pressure control were done. Patient received Low Molecular Weight Heparin and Aspirin and improved after 13 days without bleeding. Conclusions Spontaneous hepatic rupture is a rare, life-threatening presentation of APAS that warrants timely diagnosis and effective control of haemorrhage to prevent maternal and fetal mortality. Early initiation of anticoagulation is both safe and effective in preventing APAS complications. Aspirin should be initiated to prevent future thrombosis and pregnancy loss.

\section{STUDY OF CLINICAL UTILITY OF ANTIBODIES TO PHOSPHATIDYLSERINE/PROTHROMBIN COMPLEX IN INDIAN PATIENTS}

A Ganapati*, R Goel, J Kabeerdoss, M Gowri, J Mathew, D Danda. Christian Medical College - Vellore, Rheumatology, Vellore, India

\subsection{6/lupus-2017-000215.62}

Background and aims To explore utility of Antibodies to Phosphatidylserine/Prothrombin Complex (aPSPT), in Indian Anti phospholipid Syndrome (APS) patients.

Methods Data of 372 subjects whose sera was tested for aPSPT by ELISA (AESUKU,GERMANY), was retrospectively analysed. Performance of various APLs was compared using non-parametric tests. To ascertain additional utility of aPSPT, patients with suspected APS were categorised into 2 groups $i$. e. i) those with any one of criteria antibodies positive ii) those with any one APL positivity including anti- PSPT positivity.

Results In 46 patients of APS, 38 (82.60\%) had thrombotic events (21 arterial , 26 venous) and 11 ( 23.91\%) had obstetric events. Lupus anticoagulant was present in 37/46 (80.43\%) , anticardiolipin antibody in 19/46 (41.33\%), aPSPT in $17 / 46$ (36.95\%), anti- $\beta 2$ glycoprotein1 ( $\beta 2 \mathrm{GP} 1)$ IgG and IgM in 13/ $46(28.26 \%)$ and $7 / 46(15.21 \%)$ patients of APS respectively. aPSPT tested positive in $9 / 60(15 \%)$ patients with seronegative APS (SNAPS). aPSPT did not differ from other criteria APLs in any clinical parameter except compared to those with IgM B2GP-1 positivity. aPSPT was numerically more sensitive and specific than IgM B2GP1 for thrombotic, non-criteria events but less sensitive for detecting obstetric events (Table 2). Inclusion of aPSPT test in patients with suspected APS increased

Abstract 62 Tabel 1 Showing the categorization of Study subjects into patients and controls

\begin{tabular}{|l|l|l|}
\hline Type of Subjects & Number & Sub-categorization \\
\hline Total Number of Subjects & 372 & Female-331 \\
\cline { 2 - 3 } & & Male-41 \\
\hline $\begin{array}{l}\text { Definite APS (satisfying revised } \\
\text { Sapporo criteria) }\end{array}$ & 46 & Primary-20 \\
\cline { 3 - 3 } & & Secondary-26 \\
\hline Controls & 326 & $\begin{array}{l}\text { Patients with seronegative } \\
\text { APS/SNAPS)-60 }\end{array}$ \\
\cline { 3 - 3 } & & $\begin{array}{l}\text { Connective Tissue Disease } \\
\text { controls-146 }\end{array}$ \\
\cline { 3 - 3 } & & Obstetric Controls-107 \\
\cline { 3 - 3 } & & Healthy Controls-13 \\
\hline
\end{tabular}

Abstract 62 Tabel 2 Comparision of sensitivity and specificity of aPSPT and IgM anti- $\beta 2$ GP1 in definite APS patients

\begin{tabular}{|l|l|l|l|l|}
\hline Definite APS patients & \multicolumn{2}{|l|}{ Anti PSPT positive } & \multicolumn{2}{l|}{ IgM Anti-B2GP antibody positive } \\
\hline & Sensitivity & Specificity & Sensitivity & Specificity \\
\hline Obstetric Events & $27.3 \%$ & $38.5 \%$ & $45.5 \%$ & $11.5 \%$ \\
\hline Arterial Events & $38.1 \%$ & $32 \%$ & $9.5 \%$ & $24 \%$ \\
\hline Venous Events & $38.5 \%$ & $30 \%$ & $11.5 \%$ & $25 \%$ \\
\hline $\begin{array}{l}\text { Non criteria } \\
\text { manifestations }\end{array}$ & $50 \%$ & $29.4 \%$ & $16.7 \%$ & $17.6 \%$ \\
\hline
\end{tabular}

sensitivity marginally but with concomitant decrease in specificity.

Conclusions In our study, aPSPT was third most common antibody in APS patients, displaying higher sensitivity and specificity in comparison to IgM anti- $\beta 2$ GP1 for all APS manifestations except obstetric ones. SNAPS patients may test positive for aPSPT, thus endorsing its inclusion in classification criteria of APS.

\section{RITUXIMAB: IN THE MANAGEMENT OF ANTIPHOSPHOLIPID ANTIBODIES ASSOCIATED CHOREA IN A CHILD WITH LUPUS}

${ }^{1} \mathrm{~A}$ Jindal ${ }^{*},{ }^{1} \mathrm{P}$ Vignesh, ${ }^{1} \mathrm{~A}$ Gupta, ${ }^{2} \mathrm{~J}$ Ahluwalia, ${ }^{1} \mathrm{D}$ Suri, ${ }^{1} \mathrm{~A}$ Rawat, ${ }^{1} \mathrm{~S}$ Singh. ${ }^{1} \mathrm{PGIMER}$, Paediatrics, chandigarh, India; ${ }^{2}$ PGIMER, haematology, chandigarh, India

\subsection{6/lupus-2017-000215.63}

Background and aims Neuropsychiatric manifestations are noted in 50.94\% of children with lupus. Chorea, a nonthrombotic complication associated with antiphospholipid antibodies (APLA), is seen in 4\% cases.

Aim- To describe the clinical course of a child with lupus who had chorea on follow up and was treated with rituximab Methods A 10 year old girl presented with spastic quadriparesis, fever, weight loss, alopecia, oral ulcers, anaemia and thrombocytopenia. Antinuclear antibody was $4+$ diffuse pattern; and anti-dsDNA titres were $220.25 \mathrm{IU} / \mathrm{ml}$ (normal $<55 \mathrm{IU} / \mathrm{ml}$ ). T2 weighted magnetic resonance imaging (MRI) brain and spine showed multiple foci of increased signal intensity in bilateral corona radiata and centrum semiovale. She also had positive lupus anticoagulant and elevated anticardiolipin antibody titres. She received steroids, azathioprine, anticoagulants and aspirin, and showed remarkable improvement. Five years later, she was admitted with multiple joint pains and foot drop related to mononeuritis multiplex. She developed seizures and MRI brain showed diffuse cerebral atrophy with T2/FLAIR white matter hyperintensities. At 18 years of age, she presented with chorea and MRI showed periventricular T2/FLAIR hyperintensities. She responded to intravenous pulses of methylprednisolone and cyclophosphamide. Three years later, she again had similar choreiform movements with aggressive behaviour, which did not respond to haloperidol, steroids and warfarin. At this point of time, she was administered 3 doses of rituximab $\left(500 \mathrm{mg} / \mathrm{m}^{2}\right.$ at one weekly interval). 